\title{
A Controller with an Extended State Observer in Aerial Camera Position-angle System
}

\author{
Hansen Li \\ Phd Student of automation department \\ USTC \\ Heifei, China \\ hanson@mail.ustc.edu.cn
}

\author{
Yong Wang \\ Professor of Automation Department \\ USTC \\ Heifei, China \\ yongwang@ustc.edu.cn
}

\begin{abstract}
As one of the main loads of aerial reconnaissance, aerial camera has the advantages of flexibility, high efficiency and so on. In this paper, a tracking differentiator and an extended state observer are designed to control the positionangle control system of aerial camera. The simulation result is achieved and the result is satisfactory.
\end{abstract}

Keywords-aerial camera; tracking differentiator; extended state observer

\section{INTRODUCTION}

Aerial imaging and measurement techniques are used to detect ground telemetry and scene information by airborne optical system and optical coupling device [1-3]. As one of the main loads of aerial reconnaissance, aerial camera has the advantages of flexibility, high efficiency and so on [4-5].

In this paper, the position-angle system of aerial camera is studied. A tracking differentiator is designed to arrange transition process and an extended state observer is designed to compensate the disturbance and other factors. The control structure is given. And the simulation result shows that this method has a good performance.

\section{SYSTEM MODELING}

Direct-current motors have good starting, braking and speed regulation performance. Direct-current motors can start and brake quickly, turn forward and reverse. Also, direct-current motors can adjust speed smoothly and economically in a wide range. So, direct-current motors have been widely used in the field of control [6].

In our research, a direct-current torque motor is chosen as actuator in the position-angle system of aerial camera.

The voltage balance equation of armature circuit of a direct-current torque motor is shown in Equation (1) [7].

$$
\mathrm{u}=\mathrm{Ri}+\mathrm{L} \frac{\mathrm{di}}{\mathrm{dt}}+\mathrm{e}
$$

Where $\mathrm{u}$ is armature voltage (V), $\mathrm{i}$ is armature current (A), e is counter electromotive force $(\mathrm{V}), \mathrm{R}$ is armature resistance $(\Omega)$, and $L$ is armature inductance $(H)$.

When the air gap flux of each pole of direct-current motor remains unchanged, the equation can be described as Equation (2).

$$
\mathrm{e}=\mathrm{C}_{\mathrm{e}} \mathrm{Fn}=\mathrm{K}_{\mathrm{e}}^{\prime} \mathrm{W}
$$

Where $\mathrm{C}_{\mathrm{e}}$ is constant potential of a direct-current motor, $\mathrm{F}$ is flux per pole $(\mathrm{Wb}), \mathrm{n}$ is the motor's speed (r/min), $\mathrm{w}$ is the motor's angular speed (rad/s), and $\mathrm{K}_{\text {e }}^{\prime}$ means the electric potential generated by unit motor's angular speed $(\mathrm{V} /(\mathrm{rad} / \mathrm{s}))$.

When the load torque is zero, iron core loss and friction torque of motor are ignored, the torque balance equation of a direct-current motor is shown in Equation (3).

$$
\mathrm{T}_{\mathrm{em}}=\mathrm{J} \frac{\mathrm{d} \omega}{\mathrm{dt}}_{(3)}
$$

Where $T_{\mathrm{em}}$ is the electromagnetic torque of a directcurrent motor $(\mathrm{N} \cdot \mathrm{m})$, $\mathrm{J}$ is rotational inertia of a directcurrent motor $\left(\mathrm{N} \cdot \mathrm{m} \cdot \mathrm{s}^{2} / \mathrm{rad}\right.$ ).

As we know, the electromagnetic torque of a directcurrent motor is shown in Equation (4).

$$
\mathrm{T}_{\mathrm{em}}=\mathrm{C}_{\mathrm{t}} \mathrm{Fi}=\mathrm{K}_{\mathrm{t}} \mathrm{i}
$$

Where $C_{t}$ is coefficient of torque of a direct-current motor, $K_{t}$ means torque generated by unit armature current $(\mathrm{N} \cdot \mathrm{m} / \mathrm{A})$.

Equation (5) is obtained.

$$
\mathrm{u}=\frac{\mathrm{LJ}}{\mathrm{K}_{\mathrm{t}}} \frac{\mathrm{d}^{2} \mathrm{w}}{\mathrm{dt}^{2}}+\frac{\mathrm{RJ}}{\mathrm{K}_{\mathrm{t}}} \frac{\mathrm{dw}}{\mathrm{dt}}+\mathrm{K}_{\mathrm{e}} \mathrm{w}^{\mathrm{w}}
$$

After Laplace transformation, the transfer function of a direct-current torque motor can be obtained as Equation (6). 


$$
\frac{\mathrm{W}(\mathrm{s})}{\mathrm{U}(\mathrm{s})}=\frac{\mathrm{K}_{\mathrm{t}}}{\mathrm{LJs}^{2}+\mathrm{RJs}+\mathrm{K}_{\mathrm{t}} \mathrm{K}_{\mathrm{e}}^{\prime}}
$$

To identify aerial camera position-angle system. Sinusoidal signals with amplitude equal to 2000 and frequencies ranging from $0.1 \mathrm{~Hz}$ to $50 \mathrm{~Hz}$ is input, and the amplitude of the output response is obtained. The response is shown in Table I. The amplitude-frequency characteristics of the position-angle system Bird diagram can be obtained from these data. It is shown in Fig. 1. The position-angle system is approximated to a second-order linear model. The two poles of the position-angle system are 270 and 6, respectively. The second-order linear model of the positionangle system approximation is obtained as Equation (7).

$$
\frac{W(s)}{U(s)}=\frac{9}{s^{2}+276 s+1620}
$$

The state equation of the position-angle system is Equation (8).

$$
\begin{aligned}
& {\left[\begin{array}{c}
\dot{\mathrm{x}}_{1} \\
\dot{\mathrm{x}}_{2}
\end{array}\right]=\left[\begin{array}{cc}
0 & 1 \\
-1620 & -276
\end{array}\right]\left[\begin{array}{l}
\mathrm{x}_{1} \\
\mathrm{x}_{2}
\end{array}\right]+\left[\begin{array}{l}
0 \\
9
\end{array}\right] \mathrm{u}} \\
& \mathrm{W}=\left[\begin{array}{ll}
1 & 0
\end{array}\right]\left[\begin{array}{l}
\mathrm{x}_{1} \\
\mathrm{x}_{2}
\end{array}\right]
\end{aligned}
$$

\section{CONTROLLER DESIGN}

The working environment of aerial camera is complex and changeable. There will be many unpredictable external disturbances. Besides, a direct-current torque motor has dead areas, saturations, mechanical resonances and other internal factors. The system model is highly uncertain due to the large friction force and the unstable damping.

In this paper, an extended state observer is added to the aerial camera position-angle system to suppress disturbances. And this method is an error-based control method, and the

\begin{tabular}{|c|c|c|c|c|c|}
\hline \multirow{2}{*}{ Frequency/Hz } & \multicolumn{2}{|c|}{ Amplitude } & \multirow{2}{*}{ Frequency/Hz } & \multicolumn{2}{|c|}{ Amplitude } \\
\hline & Махітum & Minimum & & Maximum & Minimum \\
\hline 0.1 & 4.46 & -4.92 & 10.5 & 1.06 & -1.06 \\
\hline 0.2 & 10.08 & -9.53 & 11.0 & 1.01 & -1.01 \\
\hline 0.3 & 12.10 & -10.00 & 12.0 & 0.94 & -0.93 \\
\hline 0.4 & 12.80 & -10.30 & 13.0 & 0.86 & -0.85 \\
\hline 0.5 & 12.00 & -10.30 & 14.5 & 0.76 & -0.77 \\
\hline 0.6 & 13.90 & -10.60 & 15.0 & 0.73 & -0.74 \\
\hline 0.8 & 11.90 & -10.10 & 16.0 & 0.68 & -0.67 \\
\hline 0.9 & 11.00 & -9.80 & 17.0 & 0.64 & -0.64 \\
\hline 1.0 & 9.50 & -9.40 & 18.0 & 0.59 & -0.59 \\
\hline 1.3 & 7.98 & -8.00 & 19.0 & 0.57 & -0.55 \\
\hline 1.5 & 6.80 & -6.70 & 20.0 & 0.52 & -0.52 \\
\hline 1.7 & 6.39 & -6.38 & 21.0 & 0.50 & -0.50 \\
\hline 1.9 & 5.87 & -5.86 & 23.0 & 0.47 & -0.47 \\
\hline 2.0 & 5.33 & -5.32 & 24.0 & 0.43 & -0.43 \\
\hline 2.5 & 4.32 & -4.36 & 25.0 & 0.41 & -0.41 \\
\hline 3.0 & 3.63 & -3.65 & 27.0 & 0.38 & -0.38 \\
\hline 3.5 & 3.26 & -3.29 & 29.0 & 0.35 & -0.34 \\
\hline 4.0 & 2.83 & -2.82 & 30.0 & 0.36 & -0.34 \\
\hline 5.0 & 2.19 & -2.21 & 33.0 & 0.31 & -0.31 \\
\hline 5.5 & 2.05 & -2.06 & 35.0 & 0.29 & -0.30 \\
\hline 6.0 & 1.83 & -1.84 & 38.0 & 0.26 & -0.27 \\
\hline 7.0 & 1.54 & -1.55 & 40.0 & 0.24 & -0.25 \\
\hline 7.5 & 1.51 & -1.51 & 42.0 & 0.23 & -0.24 \\
\hline 8.0 & 1.41 & -1.40 & 45.0 & 0.21 & -0.22 \\
\hline 9.0 & 1.21 & -1.23 & 48.0 & 0.17 & -0.17 \\
\hline 10.0 & 1.12 & -1.12 & 50.0 & 0.17 & -0.18 \\
\hline
\end{tabular}
demand for precise model of the system is not high. A controller is designed.

TABLE I. 




Fig. 1. Amplitude-frequency characteristics of the position-angle system

\section{A. Tracking Differentiator}

Tracking differentiator can be used to arrange the transition process, so that a direct-current torque motor can rotate more smoothly.

The design of tracking differentiator is shown in Equation (9).

$$
\left\{\begin{array}{l}
\text { fh }=\text { fhan }\left(\mathrm{v}_{1}-\mathrm{v}, \mathrm{v}_{2}, \mathrm{r}_{0}, \mathrm{t}\right) \\
\dot{\mathrm{v}}_{1}=\mathrm{v}_{2} \\
\dot{\mathrm{v}}_{2}=\mathrm{fh}
\end{array}\right.
$$

Where $\mathrm{V}_{1}$ and $\mathrm{V}_{2}$ represent the arranged angular velocity and its differential -- angular acceleration of the transition process, respectively. And $\mathbf{V}$ is the input angular velocity. And the $t$ is the sample time. And $r_{0}$ is a parameter. And fhan $\left(\mathrm{x}_{1}, \mathrm{x}_{2}, \mathrm{r}, \mathrm{h}\right)$ is defined as Equation (10).

$$
\left\{\begin{array}{l}
d=r^{2} \\
a_{0}=h x_{2} \\
y=x_{1}+a_{0} \\
a_{1}=\sqrt{d(d+8|y|)} \\
a_{2}=a_{0}+\frac{y}{|y|}\left(a_{1}-d\right) \\
a=\left\{\begin{array}{cl}
a_{2} & |y|>d \\
a_{0}+y & |y| \leq d
\end{array}\right. \\
\text { fhan }\left(x_{1}, x_{2}, r, h\right)= \begin{cases}-r \frac{a}{|a|} & |a|>d \\
-r \frac{a}{d} & |a| \leq d\end{cases}
\end{array}\right.
$$

\section{B. Extended State Observer}

Usually, the state observer is used to observe the system state $\mathrm{X}$ and get the estimated state $\mathrm{X}^{\prime}$. General secondorder system equation of state can be written as Equation (11).

$$
\left\{\begin{array}{l}
\dot{x}_{1}=x_{2} \\
\dot{x}_{2}=f\left(x_{1}, x_{2}\right)+b u \\
y=x_{1}
\end{array}\right.
$$

For extended state observer, errors and disturbances are considered as one state of the position-angle system which describes system state together with angular velocity and angular acceleration.

Let $\mathrm{x}_{3}=\mathrm{f}\left(\mathrm{x}_{1}(\mathrm{t}), \mathrm{x}_{2}(\mathrm{t})\right)$ and $\dot{\mathrm{x}}_{3}=\mathrm{w}(\mathrm{t})$, the extended equation of state is obtained as Equation (12).

$$
\left\{\begin{array}{l}
\dot{x}_{1}=x_{2} \\
\dot{x}_{2}=x_{3}+b u \\
\dot{x}_{3}=w(t) \\
y=x_{1}
\end{array}\right.
$$

The extended state observer is designed as Equation (13).

$$
\left\{\begin{array}{l}
e=z_{1}-y \\
f=f a l(e, 0.5, t) \\
f_{1}=f a l(e, 0.25, t) \\
\dot{z}_{1}=z_{2}-B_{1} e \\
\dot{z}_{2}=z_{3}-B_{2} f+b u \\
\dot{z}_{3}=-B_{3} f_{1}
\end{array}\right.
$$

Where $B_{1}, B_{2}, B_{3}$ are parameters, $z_{1}, z_{2}, z_{3}$ are estimated states and $t$ is the sample time. And $\mathrm{fal}(\mathrm{e}, \mathrm{a}, \mathrm{h})$ is defined as Equation (14).

$$
f a l(e, a, h)= \begin{cases}|e|^{a} \frac{e}{|e|} & |e|>h \\ \frac{e}{h^{1-a}} & |e| \leq h\end{cases}
$$




\section{Control Law} (15).

In this paper, the control law is designed as Equation

$$
\mathrm{u}_{0}=\mathrm{k}_{1} \mathrm{e}_{1}+\mathrm{k}_{2} \mathrm{e}_{2}
$$

Where $\mathrm{e}_{1}$ and $\mathrm{e}_{2}$ respectively is the error of angular velocity and angular acceleration and $\mathrm{k}_{1}, \mathrm{k}_{2}$ are parameters.

Disturbances observed by extended state observer are used to compensate for $\mathrm{u}$.

$$
\mathrm{u}=\frac{\mathrm{u}_{0}-\mathrm{z}_{3}}{\mathrm{~b}}
$$

The control structure diagram is shown in Fig. 2.

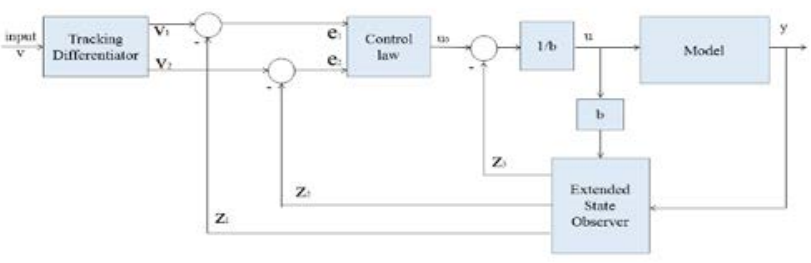

Fig. 2. Control Structure

\section{SIMULATION}

The method above is used to simulate the position-angle system. A step signal with an amplitude of 0.1 is input.

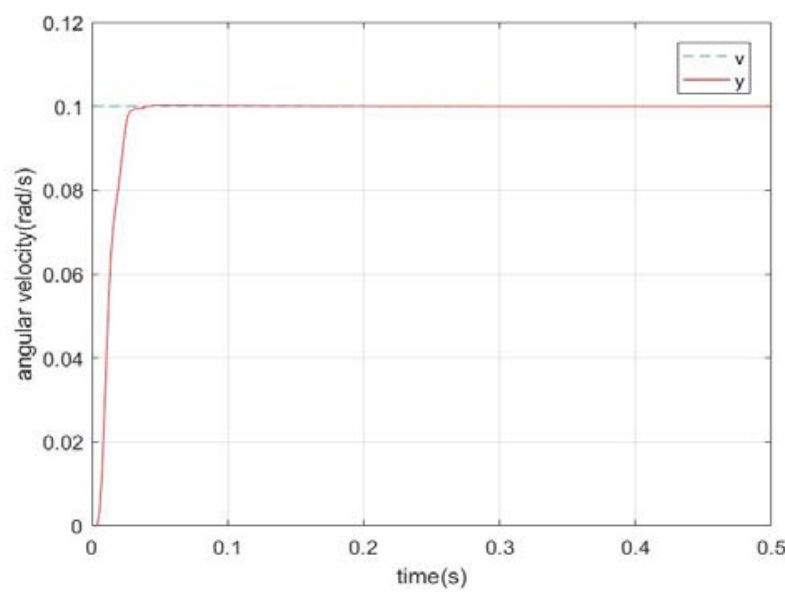

Fig. 3. System Response
The responses of the position-angle system are shown in Fig. 3. And the errors are shown in Fig. 4.

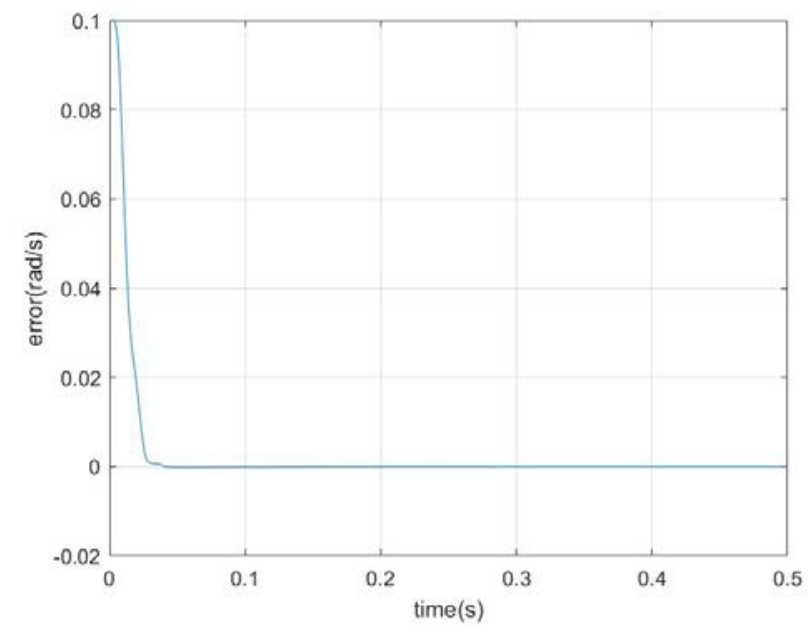

Fig. 4. Error

As can be seen from these figures, the output of the position-angle system of the aerial camera can track the given signal very quickly.

\section{CONCLUSION}

In this paper, the position-angle system of aerial camera is studied. The system model is measured and obtained. A tracking differentiator is designed to arrange the transition process of the position-angle system. At the same time, an extended state observer is designed to compensate the disturbances and other factors. And the performance is good. The signal is tracked in 0.03 seconds and the errors are within 0.0005 .

\section{REFERENCES}

[1] Meng F, Ding Y, Wang D. Analysis of Influence of Image Motion on Auto-Focus Precision for High Resolution Aerial Camera[J]. Acta Optica Sinica, 2015, 35(6):0611001

[2] J.-B.F, Y.-L.D, Q.-J.L. Application of Anti-Windup variable structure adaptive PID control to position angle control system of aerial camera[J]. Optics \& Precision Engineering, 2014, 22(3):626-632.

[3] Li X, Zhang T, Liu Z. High accuracy compensation for image surface rotation of panoramic TDICCD scanning aerial camera[J]. Acta Optica Sinica, 2014, 34(6):0611001.

[4] Struble M F. Position-angle statistics of the brightest binary galaxies in Abell clusters[J]. Astronomical Journal, 1988, 96(5):1534-1564.

[5] Zhao Q, Cao S C, Liu M. High energy electron radiography system design and simulation study of beam angle-position correlation and aperture effect on the images[J]. Nuclear Instruments \& Methods in Physics Research, 2016, 832:144-151.

[6] Demopoulos C, Kothare H, Mizuiri D. Abnormal Speech Motor Control in Individuals with 16p11.2 Deletions:[J]. Sci Rep, 2018, 8(1):1274.

[7] Cheng Y, Duan F, Cui S. The design principle of electric motors and drive systems for electric vehicles[C]// Eight International Conference on Electrical Machines \& Systems. 2005. 